increasing commercialization of agriculture, both issues that are important for contemporary programs of economic development.

Independence did not resolve the conflict between competing jural systems. Instead, the growth of African bureaucracies and the struggles for power in the new political arenas further destabilized the economy of rural communities. The optimal strategy for many rural people was to increase the diversity of their social networks and clientage to cope with the instability of resource allocation, labor availability, and pricing. Berry argues that this has been a key factor in contributing to growing economic inequality and the frequent failure of development projects, regardless of efforts to be more inclusive, participatory, and culturally sensitive.

In her final chapter, Berry reiterates the odds facing the typical African farmer: often inadequate access to land or quality of landholdings, increasing problems in mobilizing labor, constraints to large-scale irrigation development, and general economic instability. She notes that many practices of African peasants decried by agricultural scientists and development planners--planting "uneconomic" crops (e.g. cassava), intercropping, investing in marginal petty trading--are strategies to increase flexibility and reduce risk for smallholders. In her conclusion, she notes that the possibilities for successful economic development hinge on planners' appreciation of this diversity, flexibility, and change that characterize African communities. Failure to address these issues will result in continued problems in programs of economic development. Berry has written a scholarly, persuasive volume that incorporates rich case study material to support her hypotheses.

Although the volume might be too dense to be easily accessible to undergraduates, it would be an appropriate reading for any scholar examining African development and certainly for advanced students. The book would be useful both as an ethnographic source for understanding the processes of change in the 20th century in the four study areas, and as a critique and analysis of colonial and postcolonial policies and economic planning in Africa. While primarily a historical source, the implications for future policy of Berry's work is clear, and the importance of her message unquestionable.

\title{
Ethnic Groups Across National Boundaries in Mainland Southeast Asia. Gehan Wijeyewardene, editor. Singapore: Institute of Southeast Asian Studies, 1990. viii, 192 pp.
}

\author{
Reviewed by Brian L. Foster, Dean, School of Arts and Sciences, University of \\ Nebraska.
}

As its title suggests, this book is about ethnic groups whose areas cross national boundaries. The editor's introduction promises, in fact, an analytical, or even theoretical, examination of how ethnic relations are related to special features of nation states-especially features that produce states' boundedness. This is an important and difficult set of issues, and the mountains of Mainland Southeast Asia provide an ideal vehicle for studying them--a variety of nations (China, Thailand, Burma, Laos, and Vietnam) with varying degrees of political stability, boundary integrity, degrees and modes of sociopolitical integration of ethnic minorities, and a bewildering variety of ethnic groups 
with different histories and different forms and degrees of political integration (Lue, Karen, Hmong, Tai, Yao, and Mon). Unfortunately, the potential of neither the ethnological and historical nor the topical foci are realized. Although individual articles-especially Rajah's and Lilley's--are substantial contributions, and others provide useful if less penetrating material--especially Miles, Tapp, and Wijeyawardene's--the book as a whole is disappointing.

The book is one of a series of studies published by the Social Issues of Southeast Asia program of the Institute for Southeast Asian Studies at the University of Singapore. All of the articles except Miles' and Tapp's were written especially for this volume. The conceptualization of the project at the outset is not described. The variety of viewpoints the various authors bring to their articles could have been a strength for the book, collectively capturing the complexity of the broader topic. The relative weakness of several of the individual articles reduces this potential. Moreover, although the editor's introduction provides insightful comments on the issues, in my view he fails to provide a coherent framework for the papers, leaving the reader without guidance in a set of unconnected articles of uneven quality, with little value added by their being brought together in a single volume. His main contribution to integration of the papers is a facile classification scheme that is neither original nor illuminating, and a peculiar insistence that ethnicity cannot be productively defined.

Lilley's concluding chapter, in contrast, is a provocative and penetrating review of the issues that the book might have been about, drawing on the other papers here and there to illustrate a point, or taking issue as the opportunity arises. I would strongly advise readers to begin--and possibly end--their reading of the book with a careful reading of Lilley's chapter. I found the Bauer and Cholthira articles least useful, since they do not squarely address the central theme of the book, either ethnographically or topically. Bauer clearly knows more about Mons--especially Mon language and linguistics--than anyone, and there is useful information in his paper, but he is clearly not at home in this social science genre, and the material is often of marginal relevance. Cholthira's article argues for a broad historical perspective; I find it difficult to grasp the main thrust of her substantive argument about ethnicity and national boundaries.

Wijeyewardene presents fascinating material on three Thai intellectual documents published in 1988--one an epic, one a political tract, and one a history--that create different Thai identities through constructions of political and historical materials of varying kinds. These very rich materials receive less analysis than warranted, but their potential for examining the active construction of identities is considerable and suggests a potentially valuable line of research. His rather extensive descriptive presentation is especially useful, since it is unlikely that any of these works will be translated from Thai.. Rajah addresses the Karen movement, focusing especially on differences between the participation of the Karen on the Burmese and Thai sides of the border. He sees the Karen political and military organizations as aspects of a kind of nation state; he shows how the Thai-Burmese boundary becomes a resource to the Karen, and how various state "imperatives" become aspects of ethnicity for the Thai. This is a thoughtful and complex piece that doesn't really present new ethnography, but which directly addresses the topic of this book, and is a good example of what the entire book could have been.

Miles discusses two Yao villages, one in Thailand and one in China. Although they are in very different political, economic, physical, and social environments, they are in nontrivial ways Yao. He focuses on the differentiation of inheritance systems, showing how bilaterality and patrilineality developed in response respectively to commerce and land 
scarcity in the one case and of labor needs in the other. It is an excellent ethnographic comparative analysis, but its relation to the book's central topic is marginal. Nicholas Tapp, working from a dependency perspective, examines development projects among the Hmong in Thailand, showing how historical peripheralization of the Hmong was defined by many of the same external economic and political forces that gave rise to the national boundaries of the Thai state. The political and cultural status of the Hmong in Thailand, and the failure of various development projects, was determined by many of the same historical forces that produced the peripheralization that was in part being addressed by the development projects. In summary, although several of the contributions are valuable, they are somewhat uneven, and the book doesn't quite come together around the central theme indicated by the title and the editor's introduction. It is an important and difficult topic, though, and the Southeast Asian mainland is an ideal laboratory for studying it.

\title{
Forest Monks and the Nation-State: An Anthropological and Historical Study in Northeastern Thailand. By J. L. Taylor. Singapore: Institute of Southeast Asian Studies, 1993. xii + 377 pp. 6 plates.
}

\author{
Reviewed by William Galloway, University of Washington.
}

Those whose lives have been more than superficially touched by Thailand will recognize the image of wandering forest monks, "walking by themselves or in small bands in single file... patched ochreous robes the colour of burnt mustard," meditation umbrellas over their shoulders and attention focused a "plough length" ahead. Taylor's study meticulously traces the historical process by which "monks residing on the fringe of organized space and domesticated order" could be transformed into "the heart of Thai religiosity." This account will be of considerable historical value to JPE readers as the forest monks are apparently unwitting participants in their own demise, turned to instrospection as the forests of northeastern Thailand rapidly disappear. The monastic career and pupillary lineage of Ajaan Man Phuurithatto, founder of the modern "kammathaan" (ascetic meditation) forest tradition, forms the exemplary center around which Taylor's analysis unfolds.

While there have been wandering ascetics since the time of the Buddha, this type of forest monk first appears in the context of religio-political reforms integral to the process of Thai state-building during the reigns of King Mongkut (1851-68) and King Chulalongkorn (1868-1910). Taylor asserts that many such monks were "effectively frontiersmen for the nation-state in the outer provinces, caught in the nexus of prevalent social and political conditions" (136). The changing status of Man's revivified forest tradition at the periphery in relation to the still-expanding influence of the centralized Thammayut order, linked to "a pervasive patronage system with the royalty in the capital," provides the particular circumstances within which Taylor explores the universal dynamics of a doctrinal Buddhism in its most "primitive" mode of expression, "a living system of beliefs and ritual practices set in their historical and sociocultural context." 